There is no intention of "cramming too much science into the schools," but a strong case can be made out against the present cramming of classics, whether considered as a means of mental development or a preparation for life. The assumption that science is a special study, to be taken up after the age of sixteen or so, while what are called the "humanities," but are chiefly dead languages and literature, are not specialised, is a fallacy which advocates of literary learning persist in believing, though it has been exposed over and over again.

It is possible that a perverted view of Darwinism has been put forward in Germany in justification of the doctrine of "frightfulness," but naturalists as a body must not be held responsible for this conception, which was, indeed, repudiated completely by Huxley in his "Evolution and Ethics." The ancient and modern histories studied in schools and colleges are mainly concerned with wars and dynasties, and it is to these "humanities" rather than to science that we must look for the origin of the German mental condition and the conduct of the present conflict.ED., Nature.

\section{The Frequency of Snow in London.}

I THINK the number of days with snow in the early months of 1917 , as quoted in Mr. Harding's article in NATURE of April 19 according to the records of an observer at Wandsworth Common, is too low for the metropolitan district generally, inasmuch as I have recorded snowfall, chiefly at Hampstead, but partly also at Kensington, on no fewer than forty-seven days during the past winter, distributed as follows: November, I; December, 3' January, 20; February, 4 ; March, II ; April, 8; out of which forty-three belong to $1917-$ a figure nine in excess of that quoted by Mr. Harding. I do not think the discrepancy is due to Hampstead's height some three or four hundred feet above the more central parts of London, inasmuch as a difference of altitude of this small order tells more effectively upon the length of time snow lies on the ground than on its frequency of falling; but I suggest it may arise from the omission of days of very slight snowfall, of days with sleet, or, possibly, even from a failure to recognise uncommon varieties of snow.

An interesting case of an unusual variety of snow, which I heard superficial observers calling "sleet," in spite of the fact that the precipitation was entirely free from liquid drops, occurred during the week-end of January $20-2 \mathrm{r}$, when there fell in London a continuous frozen drizzle composed of fine crystalline particles, gradually whitening roofs and open spaces with a thin layer having the appearance of ordinary snow. Now, if the physical criterion of rain is the spherical drop of water, of hail the stone, pellet, or granule of compact ice, and of snow the individually formed crystal of ice, whether it falls alone, or stuck together with others in large flakes, or broken up by wind into powdery fragments, it is clear that the precipitation of January $20-2 \mathrm{I}$ had the essential character of snow, and was not a transition form between snow and rain or between snow and hail.

L. C. W. BonacrNa.

30 Parliament Hill, Hampstead, N.W.3., April 28.

\section{Scarcity of Wasps in Kashmir in 1916.}

REAding the correspondence in NATURE on the scarcity of wasps in England, and the interesting article by Prof. Carpenter (NATuRE, January 25), suggested to me that it might be worth while to record my experience in Srinagar, Kashmir, during the years $19{ }^{15}$ and 1916 , because of the curious analogy.

During the autumn of $19 \mathbf{I}_{5}$ two species of wasp were observed, one of these somewhat resembling Vespa vulgaris, and the other larger and more like a hornet. These were both excessively abundant in and around the house I occupied. The large suspended nests of both species, covered with active workers, were in almost every bush and shrub near the house and attached to the walls of the house, and it was only by repeated efforts that we could prevent the insects starting new colonies on the ceilings of the rooms in the house.

The abnormally dry season in Kashmir beginning in May, 1915, may have been specially favourable for the development of these wasps, but if so it is not easy to account for their subsequent scarcity. As in England, the year 1916 was remarkable for the rareness of wasps. The winter was mild and dry, and the shortage of rain persisted through the spring. Scarcely a single wasp of the smaller species was seen during the summer and autumn following. The only nests of the larger kind I saw were two very small ones suspended from the woodwork of the spectroheliograph, where I could daily watch the process of construction. This, however, was a most tedious operation, for after several months the nests were no larger than $I \frac{1}{2}$ in. or 2 in. in diameter-that is, about a quarter the size attained in I9I5-and instead of swarms of active workers, only one or two rather sluggish insects were seen on the nests.

The apparent despondency of the wasps in 1916 was in strong contrast with their energy during the previous season. Yet, so far as human beings could judge, the two seasons were equally inspiring as regards clear blue skies and brilliant sun.

Is it a mere coincidence that wasps of different species were one year abundant, the next year scarce, in such widely distant localities as England and Kashmir?

The Observatory, Kodaikanal, South India, March I4.

\section{Ceratonia Siliqua and the Garat Weight.}

IT is usually stated that the carat weight of jewellers and diamond merchants is derived from the hard seeds of the locust tree, Ceratonia siliqua, which were anciently used as weights. Having had occasion to obtain some of the beans, I weighed several of the seeds to see what sort of error would be incurred if they were used as weights. Out of forty-four seeds, four were shrivelled and obviously abnormal, weighing from 0.037 to $0.064 \mathrm{grm}$. each; the remaining forty seeds varied from 0.120 to $0.268 \mathrm{grm}$. The average weight of a seed was $0.2004 \mathrm{grm}$., with a probable variation of \pm 0.0235 . The median was 0.207 , and the modal average 0.204 . The variations were not well distributed. The old diamond carat, of which $151 \frac{1}{2}$ made I oz. troy, would weigh $0.205 \mathrm{grm}$.; the decimal carat now in use is $0.200 \mathrm{grm}$. It would appear, therefore, that the carat weight could be recovered with some approach to accuracy by weighing a number of seeds of the locust bean. It is also evident that the use of such seeds as weights must have given opportunities for fraudulent dealing in the precious commodities gauged by means of them, since deviations of from 30 to 40 per cent. from the average may occur. The variations in weight due to varying humidity of the air are not great; twenty-five seeds exposed to the air of a room for twenty-three hours in rainy weather gained 0.06 per cent. in weight, and after thirty-six hours over sulphuric acid lost I.7I per cent. in weight.

Utopia, Teddington, April 23.
J. H. Coste.

No. 2479 , VOL. 99] 